\title{
Роль российских лесов в реализации Парижского климатического соглашения: возможности или риски ${ }^{1}$
}

А.И. ПыЖЕВ, кандидат экономических наук. E-mail: apyzhev@sfu-kras.ru Е.А. ВАГАНОВ, академик РАН, доктор биологических наук, Сибирский федеральный университет, Красноярск. E-mail: research@sfu-kras.ru

Аннотация. Парижское соглашение 2015 г. в русле Рамочной конвенции $\mathrm{OOH}$ по изменению климата задало новый формат международной координации усилий по управлению выбросами парниковых газов с учетом национальных интересов и императива повсеместного перехода к низкоуглеродной энергетике. В статье рассмотрены возможности использования потенциала поглощения углерода российскими лесами с точки зрения формулирования и реализации обязательств России в рамках Парижского соглашения по климату 2015 г. Проанализированы экономические последствия неопределенности оценок углеродного бюджета российских лесов. Показано, что задача сокращения объема антропогенных выбросов парниковых газов с учетом интересов развития национальной экономики требует развития методик и информационной базы оценки бюджета углерода российских лесов. Предлагается начать работу по формированию комплексной стратегии участия страны в реализации Парижского соглашения с учетом как целей технологической модернизации энергетической отрасли, так и увеличения площади лесов, а также полноты и достоверности информации об их качестве.

Ключевые слова: экономика климатических изменений; Парижское соглашение по климату; экономика лесного хозяйства; депонирование углерода; парниковые газы

Изменение климата стало новым глобальным вызовом, всё более явно воспринимаемым обществом в целом и определенной частью экспертов и политиков как источник потенциальной опасности для населения и материальных активов, накопленных человечеством за всю его историю. Климатическая динамика может отразиться не только на социальном благосостоянии, но также и на окружающей природной среде, которая служит как местом обитания человека, так и ресурсной базой, обеспечивающей удовлетворение потребностей общества.

${ }^{1}$ Исследование выполнено за счет гранта Российского научного фонда (проект № 19-18-00145). Авторы выражают признательность рецензенту за замечания, которые помогли существенно расширить и уточнить материал статьи и улучшить ее структуру, а также Р. В. Гордееву и Д. В. Андрющенко. 
Климат Земли меняется в течение всей ее геофизической истории, однако начиная с 1950-х гг. на планете происходят изменения, которые существенно отличаются от наблюдавшихся ранее: температура атмосферы и океана увеличивается, количество снега и льда сокращается, а уровень мирового океана поднимается. Комплексные исследования, проведенные Межправительственной группой экспертов по изменению климата (Intergovernmental Panel on Climate Change), показали, что с 1880 г. по 2012 г. средняя температура на поверхности океана и суши выросла на $0,85 \pm 0,2{ }^{\circ} \mathrm{C}$ и описывается устойчивым линейным трендом, сохранение которого может привести к еще более выраженному потеплению ${ }^{2}$. В соответствии с наиболее распространенной гипотезой, объясняющей данную тенденцию, происходящие изменения вызваны резким увеличением концентрации антропогенных выбросов парниковых газов (в частности, диоксида углерода) в атмосферу вследствие интенсивного развития промышленности во второй половине $\mathrm{XX}$ в $^{3}$.

Важнейшими проявлениями воздействия глобального потепления на хозяйственную деятельность человека стали природные катастрофы (штормы, наводнения, засухи, лесные пожары, массовое размножение фитофагов и др.) и процессы постепенной деградации экосистем [Porfiriev, 2015]. Первая группа механизмов не остается незамеченной в силу мгновенного и объемного ущерба здоровью и жизни населения, потери производительных активов и инфраструктуры. Вторая же группа - долгосрочные процессы - из-за своей неявной выраженности находятся на периферии общественного дискурса. Однако именно они, по нашему мнению, требуют особого внимания исследователей, поскольку вызванный ими «эффект домино» может привести к гораздо более масштабным и опасным последствиям.

\footnotetext{
${ }^{2}$ IPCC, 2014. Climate change 2014: Synthesis Report. Intergovernmental Panel on Climate Change. URL: http://www.ipcc.ch/pdf/assessment-report/ar5/syr/SYR_AR5_FINAL_full_ ru.pdf (дата обращения: 23.04.2017).

${ }^{3}$ Напряженная дискуссия относительно причин глобального потепления привела к публикации ряда исследований, посвященных определению доли сторонников гипотезы об антропогенных причинах данного явления в общем пуле экспертов по проблематике климатических изменений. Разброс оценок такой доли колеблется от 90 до $100 \%$, причем последняя и наиболее влиятельная работа по данному вопросу, в которой были проанализированы более 11 тысяч актуальных статей, проиндексированных библиометрической базой данных Web of Science, утверждает, что консенсус составляет не менее 97\% [Cook et al., 2016].
} 
В развитых странах проблема климатических изменений вызывает обеспокоенность элит главным образом в связи с возможным глобальным перераспределением ресурсов планеты. Так, если не взять процесс под контроль и не научиться управлять им, территории с наиболее комфортными на сегодняшний день условиями для проживания и ведения хозяйственной деятельности (прежде всего, Центральная и Южная Европа, Соединенные Штаты Америки) рано или поздно могут уступить в своей привлекательности северным районам планеты. Очевидно, это одна из причин распространения в крупных странах мира идеи о приобретении малоосвоенных арктических территорий. Представляется, что в свое время эти идеи найдут практическое воплощение 4 .

\section{Экономические механизмы решения проблемы изменения климата: дефицит успеха}

С точки зрения современной экономической теории проблема глобального потепления - наиболее масштабный из известных примеров провала рынка. Данную ситуацию традиционно объясняют трагедией общих ресурсов (англ. tragedy of the commons) - явлением деградации общедоступного блага при наличии естественных противоречий в интересах его пользователей [Hardin, 1968].

Несмотря на то, что идея Г. Хардина широко используется для объяснения причин усугубления проблемы глобальных климатических изменений и, по сути, стала основой для развития международных климатических инициатив, она не дала экономических механизмов, которые могли бы на практике переломить тенденции увеличения антропогенных выбросов парниковых газов. К полувековому юбилею с момента появления работы Хардина вышел ряд публикаций, в которых развивается тезис о том, что решение обсуждаемой проблемы может быть достигнуто путем привития населению планеты и, прежде всего, лицам, принимающим решения, ответственного отношения к природе

\footnotetext{
${ }^{4}$ Трамп назвал «стратегически интересной» идею покупки Гренландии // Ведомости. 2019. 19 авг. URL: https://www.vedomosti.ru/politics/news/2019/08/19/809078-trampgrenlandii
} 
и долгосрочным последствиям хозяйственной деятельности [Brown et al., 2019] $]^{5}$.

Развитие экономических подходов к решению проблемы глобальных климатических изменений позволило создать два класса инструментов для интернализации внешнего эффекта (провала рынка), вызванного глобальным потеплением: взимание «углеродного» налога и систему торговли квотами на выбросы (англ. cap-and-trade). Однако глобальные инициативы, разработанные и принятые для их практической реализации (Рамочная конвенция ООН об изменении климата и Киотский протокол ${ }^{6}$ ), не принесли прогресса. Подробный анализ того, как и почему это произошло, проводился и российскими, и зарубежными исследователями [Макаров, 2011].

Разумеется, о категорическом отрицании всякого результата речи не идет. Так, например, с помощью эконометрического моделирования было показано, что страны, ратифицировавшие Киотский протокол, сократили выбросы углекислого газа в среднем на 7\%. Однако это еще не доказывает, что данного эффекта не было бы в отсутствие принятых обязательств [Grunewald, Martinez-Zarzoso, 2016]. Кроме того, даже если отнести этот успех на счет Киотской инициативы, ее цели по удержанию роста температуры воздуха в пределах $2{ }^{\circ} \mathrm{C}$ относительно допромышленного уровня так и не были достигнуты. Налог на выбросы парниковых газов ввели лишь некоторые развитые страны ${ }^{7}$ (в порядке эксперимента), поэтому глобальный дефицит инвестиций

\footnotetext{
${ }^{5}$ Определенные успехи в этом направлении достигнуты в развитых странах Европы и США, где в последние десятилетия развивается своего рода культ «зеленого» мышления, однако подобные ценности пока еще не разделяет большая часть населения планеты, что не позволяет надеяться на глобальное сокращение выбросов парниковых газов. По всей видимости, теоретической базой для таких механизмов в будущем станут разработки на основе теории игр, в частности, стохастических и эволюционных игр, предполагающие, что кооперативное поведение сторон позволяет добиваться более высоких выигрышей в долгосрочной перспективе [Hilbe et al., 2018].

${ }^{6}$ Киотский протокол к Рамочной конвенции Организации Объединенных Наций об изменении климата. Принят 11 декабря 1997 года. URL: http://www.un.org/ru/documents/ decl_conv/conventions/kyoto.shtml (дата обращения: 25.05.2019).

${ }^{7}$ Необходимо отметить, что, в отличие от успешного внедрения экологического налогообложения (налогов на загрязнение атмосферы, почвы и водных объектов), примеров действующей практики налогообложения выбросов парниковых газов, которая бы оказывала существенное независимое влияние на сокращение объема антропогенных выбросов, немного [Мотосова, Потравный, 2014].
} 
в решение проблемы парникового эффекта с течением времени лишь возрастает.

Фокус нашего внимания сосредоточен на актуальном для сегодняшней повестки дня Парижском климатическом соглашении Рамочной конвенции ООН об изменении климата (РКИК). Документ принят в 2015 г. с целью разработки и внедрения мер по ограничению повышения глобальной температуры воздуха $2{ }^{\circ} \mathrm{C}$ по сравнению с показателями доиндустриальной эпохи ${ }^{8}$. Страны - участницы соглашения признали необходимость уменьшения существующих объемов выбросов к 2030 г. и полного их прекращения к 2050 г. В частности, Россия подтвердила намерение и фактическую реализацию обязательства по сокращению выбросов в масштабах всей национальной экономики к 2030 г. на 25-30\% по сравнению с 1990 г. ${ }^{9}$

Необходимо отметить, что вопреки распространенному мнению о том, что Парижское соглашение формально пришло на смену Киотскому, РКИК ООН рассматривает эти международные инициативы как два различных инструмента глобальной климатической политики. Работа по имплементации Парижского соглашения де-юре не отменяет ранее принятых обязательств стран по Киотскому протоколу, хотя де-факто предполагает принципиально иной подход к процессу сокращения антропогенных выбросов $\mathrm{CO}_{2}$ [Вирт, 2017].

Парижское соглашение представляет собой гораздо более гибкий формат международной координации усилий по управлению выбросами парниковых газов, исходя из наблюдающегося многообразия национальных интересов и императива перехода к низкоуглеродной энергетике. В отличие от Киотского протокола, который предписывал обязательства по сокращению выбросов лишь отдельным государствам по принципу «сверху-вниз», Парижское соглашение предоставляет странам-участницам свободу в формулировании национального вклада в решение проблемы

\footnotetext{
${ }^{8}$ Парижское соглашение. Организация Объединенных Наций. Принято 12 декабря 2015 года. URL: https:/unfccc.int/sites/default/files/russian_paris_agreement.pdf (дата обращения: 23.06.2019).

${ }^{9}$ В 2017 г. выбросы парниковых газов в России составили 67,6\% от уровня 1990 г. без учета сектора землепользования, изменений в землепользовании и лесного хозяйства (ЗИЗЛХ) и 50,7\% с его учетом. Источник: Национальный доклад о кадастре антропогенных выбросов из источников и абсорбции поглотителями парниковых газов, не регулируемых Монреальским протоколом, за 1990-2017 гг. / Росгидромет. М., 2019.
} 
глобального потепления. Такой полицентрический характер принятия решений позволяет отдельным странам вести самостоятельную политику контроля за выбросами парниковых газов с учетом особенностей их политического устройства, структуры и динамики экономики. Именно этот факт подчеркивает исключительную важность выработки национальной климатической политики.

Климатические изменения при определенных условиях могут создавать потенциальные возможности экономического развития. Это, в частности, касается России, большая часть территории которой может стать гораздо привлекательнее для жизни и ведения экономической деятельности при смягчении климата. Особенно выраженное влияние, очевидно, будет оказано на лесное и сельское хозяйство [Чугункова и др., 2018]. Однако адаптационная способность лесов бореальной зоны к резкому потеплению климата всё еще недостаточно изучена, а потому плохо предсказуема. Некоторые исследователи полагают, что при потеплении среднегодовой температуры воздуха на $3{ }^{\circ} \mathrm{C}$ бореальные леса могут стать «элементом переключения» (англ. tipping element), т.е. вступят в фазу неустойчивого состояния, когда относительно небольшие изменения внешней среды приводят к нелинейному отклику и ненулевой обратной связи в функционировании экосистемы и гибели ее отдельных элементов [Lenton et al., 2008]. Кроме того, в качестве одной из важных угроз национальной безопасности России следует рассматривать риск захвата отдельных ее территорий субъектами стран, в которых условия жизни ухудшатся в результате глобального потепления.

С точки зрения национальных интересов, имплементация Парижского соглашения может стать как одним из важных драйверов модернизации экономики страны, так и искусственно ограничить ее развитие.

\section{Роль российских лесов в процессе сокращения выбросов парниковых газов}

Леса играют важную роль в глобальном углеродном цикле, обеспечивая основную часть стока углерода ${ }^{10}$ в растительные экосистемы. Депонируя избыточный объем $\mathrm{CO}_{2}$ из атмосферы, леса тем

\footnotetext{
10 Здесь и далее под стоком углерода понимается объем углекислого газа $\left(\mathrm{CO}_{2}\right)$,
} находящегося в тканях растений. 
самым вносят важнейший вклад в мировой баланс климата. Почти треть (32\%) глобальных запасов углерода поглощают бореальные лесные экосистемы ${ }^{11}, 38 \%$ из которых расположены в России.

Парижское соглашение, учитывая депонирующую способность лесов, обязывает страны-участницы предпринимать все необходимые меры для их сохранения, поощряет международные проекты в данной области. Формирование национальной климатической политики должно опираться на глубокий анализ текущего и ретроспективного состояния поглощающей способности лесов, однако все осложняет чрезвычайное многообразие методов, применяемых для получения такого рода оценок. Здесь и дистанционное зондирование Земли, и наблюдения за концентрациями парниковых газов в атмосфере, и большое количество различных методик наземной инвентаризации лесов.

В соответствии с Парижским соглашением, информационной базой для выработки национальных климатических стратегий должна стать отчетность по объему выбросов парниковых газов с учетом сектора землепользования, изменения в землепользовании и лесного хозяйства (ЗИЗЛХ) ${ }^{12}$, которая уже более двадцати лет регулярно предоставляется в рамках РКИК и, в частности, Киотского протокола [Кокорин, Луговая, 2018]. В России такие отчеты составляет Институт глобального климата и экологии Росгидромета и РАН на основе расчетов с применением методики Региональной оценки бюджета углерода лесов (РОБУЛ), разработанной в Центре по проблемам экологии и продуктивности лесов РАН [Романовская и др., 2018]. Доклад представляет собой национальный кадастр антропогенных выбросов из источников и абсорбции поглотителями всех парниковых газов, систематизированный по источникам выбросов (секторам).

В середине 2017 г. Министерство природных ресурсов и экологии утвердило Методические указания по количественному

\footnotetext{
${ }^{11}$ Существует устоявшаяся классификация лесов на тропические, умеренные и бореальные. Бореальными называют таежные северные леса, как правило, располагающиеся от 50 до $70^{\circ}$ северной широты. На бореальные леса приходится 272 \pm 23 трлн т запасов углерода, в то время как на тропические $-471 \pm 93$ трлн т [Pan et al., 2011].

${ }^{12}$ Сектор землепользования, изменения в землепользовании и лесного хозяйства (от англ. Land Use, Land Use Change and Forestry) признается важнейшим источником антропогенных выбросов парниковых газов, поэтому усилия по оценке углеродного бюджета сосредоточены именно на нем.
} 
определению объема поглощения парниковых газов ${ }^{13}$ (Методические указания), которые основываются на методике РОБУЛ, и будут применяться для формирования отчетности в рамках Парижского соглашения. Таким образом, официально установлено, что учет углерод-поглощающей способности в рамках выполнения национальных обязательств России по объему выбросов $\mathrm{CO}_{2}$ будет вестись на основе методики РОБУЛ и информационной базы Государственного лесного реестра.

Принятие Методических указаний возобновило давнюю дискуссию о преимуществах и недостатках оценочных подходов, переместившуюся с трибун научных конференций и страниц академических изданий в общественно-политическую плоскость ${ }^{14,15}$. Остроты дискуссии добавляют заметные расхождения в количественных оценках объема стока углерода от сектора ЗИЗЛХ, полученных разными исследовательскими коллективами (таблица).

Оценки стока углерода в сектор ЗИзлХ в России, полученные отдельными исследовательскими группами

\begin{tabular}{|c|c|c|}
\hline Методика (источник) & Официальное применение & $\begin{array}{c}\text { Оцененный сток углерода, } \\
\text { млн т в год }\end{array}$ \\
\hline $\begin{array}{l}\text { РОБуЛ [Замолодчиков и др., } \\
\text { 2011] }\end{array}$ & $\begin{array}{l}\text { Национальный кадастрантропоген- } \\
\text { ныхвыбросов иабсорбциипарнико- } \\
\text { вых газов. Методика определения } \\
\text { объема поглощения парниковых } \\
\text { газов Минприроды России }\end{array}$ & $230-240$ \\
\hline $\begin{array}{l}\text { Всероссийский НИИ лесовод- } \\
\text { ства и механизации лесного } \\
\text { хозяйства [Фёдоров, 2017] }\end{array}$ & $\begin{array}{l}\text { Отчетность России для Продоволь- } \\
\text { ственной и сельскохозяйственной } \\
\text { организации ООН (FAO) }\end{array}$ & $630 \pm 110$ \\
\hline $\begin{array}{l}\text { Интегральная земельная ин- } \\
\text { формационная система IIASA } \\
{\text { (Австрия) }{ }^{\star \star}}_{\text {[Швиденко, Ще- }} \\
\text { пащенко, 2014; Shvidenko et } \\
\text { al., 2015] }\end{array}$ & - & $\begin{array}{c}546 \pm 120 \\
\text { (среднее за 2007-2009 гг.) } \\
650 \pm 130 \\
\text { (среднее за 2000-2012 гг.) }\end{array}$ \\
\hline
\end{tabular}

*Национальный доклад о кадастре разрабатывается и представляется в соответствии с обязательствами Российской Федерации согласно Рамочной конвенции ООН, об изменении климата и Киотскому протоколу к Рамочной конвенции ООН об изменении климата. Ч. 1. М., 2017. URL: http://www.meteorf.ru/ upload/pdf_download/NIR-2017_v1_fin.pdf (дата обращения: 01.06.2019).

** IIASA - Международный институт прикладного системного анализа.

\footnotetext{
${ }^{13}$ Утв. распоряжением Минприроды России от 30.06.2017 № 20-p.

${ }^{14}$ Кудияров С. Идите вы лесом // Эксперт. 2017. № 43 (1049). URL: https:/expert.ru/ expert/2017/43/idite-vyi-lesom/

${ }^{15}$ Тихомирова Я. Чем российские леса хуже зарубежных // Газета.Ру. 2017. 8 авг. URL: https://www.gazeta.ru/science/2017/08/07_a_10822279.shtml?updated
} 
Помимо упомянутой системы РОБУЛ, существует еще ряд оригинальных разработок, решающих схожую задачу (оговоримся, что мы здесь рассматриваем только работы коллективов, принявших активное участие в обсуждении Методических указаний, более подробный анализ существующих методик и оценок бюджета углерода российских лесов содержится в соответствующих обзорах [Замолодчиков, 2011; Малышева и др., 2017]).

Альтернативный подход к оценке углеродного бюджета российских лесов развивает Всероссийский НИИ лесоводства и механизации лесного хозяйства (ВНИИЛМ) в рамках выполнения обязательств по предоставлению отчетности России для Продовольственной и сельскохозяйственной организации ООН.

Он также использует в качестве исходной информации данные Государственного лесного реестра. Но в отличие от методики РОБУЛ, где один из главнейших показателей углеродного бюджета - сток углерода в фитомассу (биомассу живых растений лесной экосистемы) - оценивается через разницу запасов древостоев последовательных возрастных групп (молодняк, средневозрастные, приспевающие, спелые и перестойные насаждения) путем применения конверсионных коэффициентов, во ВНИИЛМ результат оценки достигается через вычисление среднего прироста древостоев, то есть путем деления суммарного запаса живой и мертвой фитомассы по группам возраста на средний возраст древостоев. Итоговые результаты расчетов различаются практически в три раза (таблица). При этом отметим, что используемые в обеих методиках официальные данные Государственного лесного реестра примерно для половины лесного покрова давно устарели, и их точность неизвестна.

Альтернативные оценки могут быть получены с помощью применения многометодных систем, опирающихся, помимо официальных данных наземной инвентаризации, на спутниковую информацию о земельном покрове, ландшафтах и экосистемах и результаты различных наземных измерений, и использующих для расчетов сложные математические модели. Один из примеров таких исследований - работы коллектива IIASA (Австрия) в рамках развития Интегральной земельной информационной системы (ИЗИС), реализующей системный подход к полному и верифицированному учету углеродного бюджета. Оценки, полученные с помощью методики IIASA, нашли отражение в авторитетных 
зарубежных и российских исследованиях [Швиденко, Щепащенко, 2014; Shvidenko et al., 2015; Pan et al., 2011].

Отметим, что итоговая оценка стока углерода в лесные экосистемы России, полученная по этой методике, существенно ближе к результатам расчетов по модели ВНИИЛМ, чем по РОБУЛ. Методические источники этих расхождений в оценках подробно описаны, в том числе в работах авторов самой РОБУЛ [Замолодчиков и др., 2011; Швиденко, Щепащенко, 2014]. По сути, они связаны с теми ограничениями и целями, которые присущи каждой из рассматриваемых методик. Подходы РОБУЛ и ВНИИЛМ разрабатывались для составления отчетов для международных организаций в соответствии с установленными ими правилами. Работы же других коллективов были свободны от ограничений по источникам исходных данных и носили преимущественно академический характер.

Таким образом, каждый из перечисленных подходов предназначается для решения своей, довольно узкой задачи. С одной стороны, это предопределяет систематические различия в результатах оценивания. С другой - затрудняет (и методически, и политически) гармонизацию этих подходов. По всей видимости, основные усилия должны быть направлены на исправление самого слабого звена в системе оценки потенциала углеродного стока российских лесов - низкого качества данных Государственного лесного реестра. Именно разработка новой системы учета лесного покрова, которая на современной информационнометодической основе объединила бы традиционное лесоустройство, национальную (государственную) инвентаризацию лесов и лесной мониторинг, стала бы не только важнейшим фактором получения адекватной и непротиворечивой оценки углеродного бюджета российских лесов, но и существенно улучшила бы качество управления лесным хозяйством в целом.

\section{Экономические последствия неопределенности оценок углеродного бюджета российских лесов}

Участие России в реализации целей Парижского соглашения по климату 2015 г. требует глубокого содержательного анализа его последствий, прежде всего, исходя из учета интересов развития экономики страны. 
Приведенные различия в оценках стока углерода в лесные экосистемы могут иметь вполне конкретное экономическое измерение. Так, если оценить возможную сумму углеродного налога для компании-эмитента в 20 долл. США за 1 т $\mathrm{CO}_{2}$ (что соответствует нижнему уровню, предлагаемому IPCC), то только разница в вышеприведенных оценках стока углерода в леса России (таблица) даст разброс в 7,9 млрд долл. в год, что сопоставимо с рыночной капитализацией крупных российских металлургических компаний $^{16}$. Верхний же уровень цены углерода в 150 долл. даст разброс уже в 46,7 млрд долл. - сумма, сравнимая с капитализацией любой из первой пятерки крупнейших российских компаний ${ }^{17}$. Причем в данном примере расчеты приведены для базового (умеренного) сценария IPCC, предусматривающего удержание роста средней температуры на планете в пределах $2{ }^{\circ} \mathrm{C}$ на горизонте до 2100 г. Если же иметь в виду вариант сдерживания роста температуры в пределах $1,5^{\circ} \mathrm{C}$, цена за выброс тонны углерода должна составить от 140 до 590 долл. США.

Другой аспект современных глобальных климатических инициатив, вызывающий справедливую настороженность России, связан с тем, что они по сути своей протежируют сектор альтернативной энергетики, активно развивающийся в последние десятилетия в ведущих странах мира [Порфирьев, 2018]. Наукоемким компаниям данного сектора, выросшим до текущей рыночной капитализации в 4 трлн долл., ${ }^{18}$ и стоящим за ними государственным лоббистам в экономически развитых странах Европы, США и Китае, необходимы поддержка и создание условий для сбыта «зеленых» технологий в менее развитые страны. Идеология климатических соглашений подразумевает, что Россия, как и другие государства, экономика которых основана на добыче и переработке природных ресурсов с интенсивным углеродным следом, должна будет не только заплатить

\footnotetext{
${ }^{16}$ По данным РИА Рейтинг на конец 2018 г., капитализация АО «РУСАЛ»-6,7 млрд долл. США, ПАО «Магнитогорский металлургический комбинат»-6,9 млрд долл., ООО «ЕвразХолдинг»-8,8 млрд долл. Рейтинг самых дорогих публичных российских компаний - 2019. URL: http://riarating.ru/infografika/20190129/630115992.html (дата обращения: 10.08.2019).

${ }^{17}$ ПАО «НК „Роснефть“»-65,3 млрд долл. США, ПАО «Лукойл»-53,8 млрд долл., НОВАТЭК - 49,4 млрд долл. [Там же].

${ }^{18}$ UNFCCC. Green Economy Overtaking Fossil Fuel Industry - FTSE Russel Report. URL: https://unfccc.int/news/green-economy-overtaking-fossil-fuel-industry-ftse-russel-report (дата обращения: 13.08.2019).
} 
за сокращение выбросов парниковых газов, но и нести все издержки в связи с существенным сжатием основных секторов ее экономики. Разумеется, это в корне противоречит не только интересам отечественного топливно-энергетического комплекса, но и населения страны в целом.

Тем не менее отказ от участия в климатических инициативах, включая Парижское соглашение, нельзя признать конструктивным решением хотя бы потому, что игнорирование тенденции изменения мирового энергобаланса может привести к структурному экономическому кризису уже в среднесрочной перспективе. Нашей стране необходима взвешенная и планомерная климатическая политика, исходящая из такой парадигмы развития, которая не просто не ухудшает текущее положение отдельных секторов экономики, а, напротив, работает на их долгосрочный рост.

\section{Какой может быть оптимальная климатическая политика России?}

Представляется, что работу необходимо вести в двух направлениях: создание экономических стимулов для снижения антропогенных выбросов парниковых газов и одновременное увеличение потенциальной поглощающей способности лесов.

Для решения первой задачи необходимо, в частности, обратить внимание на комплексное развитие энергетики на возобновляемых источниках (ВИЭ), уровень внедрения которой пока существенно уступает ведущим странам мира [Порфирьев, Рогинко, 2016]. Стимулирование развития данного сектора может заложить основу для серьезной технологической модернизации системы внутреннего обеспечения энергоресурсами. Приоритет в реализации такого рода проектов, по нашему мнению, должен принадлежать компаниям отраслей традиционного природопользования (прежде всего, нефтегазовой, угольной промышленности) и металлургии, что позволит не только значительно повысить уровень диверсификации их бизнесов, но и обеспечить устойчивое социально-экономическое развитие зависимых от них территорий.

Вторая задача решается за счет наращивания площади и качества российских лесов. В этом смысле важным (хоть и, очевидно, побочным) следствием реализуемой в рамках национального проекта «Экология» федерального проекта «Сохранение лесов» является существенное увеличение площади лесовосстановления 
[Пыжев, 2019]. Эту работу выполняют не только лесозаготовители, которые обязаны восстанавливать вырубки в рамках договоров аренды, но и компании других отраслей. Так, компания «РУСАЛ» на условиях частно-государственного партнерства взяла на себя обязательства по посадке 1 млн деревьев на площади 250 га в Красноярском крае и Иркутской области в рамках пилотного проекта по увеличению объема поглощения углекислого газа в компенсацию выбросов, которые производят принадлежащие ей предприятия ${ }^{19,20}$. Таким образом АО «РУСАЛ» решает следующие задачи: 1) реализация стратегической инициативы в рамках национальных проектов, участие в которых де-факто обязательно для крупных российских компаний; 2) снижение углеродного следа своей продукции за счет компенсации части выбросов. Последний аспект важен не только в рамках выполнения национальных обязательств по Парижскому соглашению, но и для продвижения продукции компании на рынки западных стран.

Однако даже предусмотренное проектом доведение к 2024 г. площади лесовосстановления и лесоразведения до 100\% относительно площади вырубленных и погибших насаждений (в 2018 г. - 62,3\%) не способно существенно изменить перспективный углеродный баланс лесов. Дело в том, что искусственные (плантационные) лесные насаждения поглощают до 40 раз меныший объем парниковых газов по сравнению с естественными лесами [Lewis et al., 2019]. В частности, по расчетам авторов названной работы, новые естественные леса могут дополнительно депонировать около 116 т углерода с 1 га площади к 2100 г. В то же время высаженный «РУСАЛОМ» новый лес только на 13-й год начнет поглощать 5 т углерода на 1 га $^{21}$. Таким образом, для увеличения собственно поглощающей способности российских лесов следует сосредоточить основные усилия

\footnotetext{
${ }^{19}$ Рослесхоз, «РУСАЛ» и правительство Иркутской области договорились о реализации на территории региона проектов в области поглощения парниковых газов. Министерство природных ресурсов и экологии России. 2019. 6 июн. URL: http:/www.mnr.gov.ru/press/ news/rosleskhoz_rusal_i_pravitelstvo_irkutskoy_oblasti_dogovorilis_o_realizatsii_na_territorii_regiona_pr/?special_version=Y (дата обращения: 22.06.2019).

20 «РУСАЛ» посадит 1 млн деревьев в лесах России. TACC. 2019. 30 мар. URL: https://tass.ru/obschestvo/6276758 (дата обращения: 22.06.2019).

${ }^{21}$ «РУСАЛ» запустил масштабный проект по лесовосстановлению в Красноярском крае // Аргументы и факты. 21 мая 2019. URL: https://krsk.aif.ru/society/rusal_zapustil_ masshtabnyy_proekt_po_lesovosstanovleniyu_v_krasnoyarskom_krae (дата обращения: 17.08.2019).
} 
на содействии естественному возобновлению леса (проведение соответствующих лесохозяйственных мероприятий, экономикоправовая защита естественных лесов от использования в иных хозяйственных нуждах и т.д.).

\section{Заключение}

Подписав Парижское соглашение по климату, Россия обязалась всемерно способствовать сдерживанию глобального потепления. Однако реализации этих обязательств препятствует отсутствие научного и политико-экономического консенсуса относительно оценки углеродного бюджета России, исходя из которой должен определяться ее вклад в решение проблемы глобальных климатических изменений. Эта оценка состоит из двух больших составляющих: объема антропогенной эмиссии парниковых газов и поглощающей способности российских лесов как важнейшего депонента углерода в наземных экосистемах. Споры разгорелись именно относительно последней, поскольку результаты оценок, выполненных разными коллективами, различаются в несколько раз. Помимо прочего, такой разброс формирует значительную разницу в суммах платежей за выбросы, которые лягут на крупнейших российских производителей, эмитирующих парниковые газы.

Поскольку проблема носит не только научный, но и прикладной характер, затрагивая экономические интересы отдельных компаний, секторов экономики и страны в целом, принятие решений по конкретным обязательствам России следует вести весьма осторожно, чтобы потенциальные возможности использования и наращивания потенциала углерод-поглощающей способности российских лесов не превратились в риски и ограничения для развития экономики страны.

В целом авторы пришли к выводу о необходимости разработки комплексной стратегии участия России в Парижской инициативе. Представляется, что такая стратегия должна учитывать, как минимум, три ключевых направления. Вопервых, развитие энергетики на ВИЭ внутри страны с целью технологической модернизации российской промышленности и гибкого встраивания в мировые тренды изменения баланса энергопотребления. Во-вторых, необходимо существенно увеличить площадь и повысить качество российских лесов 
за счет создания условий для естественного возобновления леса и усиления работы по искусственному лесовосстановлению, уже проводимой в рамках федерального проекта «Сохранение лесов». В-третьих, не менее важно обеспечить совершенствование системы сбора и представления информации Государственного лесного реестра, без чего невозможно составить точное и научно обоснованное знание о действительной поглощающей способности российских лесов.

\section{Литература}

Вирт Д. А. Парижское соглашение: новый компонент климатического режима ООН // Вестник международных организаций. 2017. Т. 12. № 4. С. 185-214.

Замолодчиков Д. Системы оценки и прогноза запасов углерода в лесных экосистемах // Устойчивое лесопользование. 2011. № 4 (29). С. 15-22.

Замолодчиков Д.Г., Грабовский В.И., Краев Г.Н. Динамика бюджета углерода лесов России за два последних десятилетия // Лесоведение. 2011. № 6. C. $16-28$.

Кокорин А., Луговая Д. Поглощение $\mathrm{CO}_{2}$ лесами России в контексте Парижского соглашения // Устойчивое лесопользование. 2018. № 2 (54). С. 13-18.

Макаров И. «Двойной дивиденд» вместо глобального альтруизма // Россия в глобальной политике. 2011. Т. 9. № 4. С. 142-154.

Мальишева Н.В., Моисеев Б. Н., Филипчук А.Н., Золина Т.А. Методы оценки баланса углерода в лесных экосистемах и возможности их использования для расчетов годичного депонирования углерода // Лесной вестник. 2017. Т. 21. № 1. C. 4-13. DOI: 10.18698/2542-1468-2017-1-4-13

Мотосова Е.А., Потравный И.М. Плюсы и минусы введения углеродного налога: зарубежный опыт и позиция России по Киотскому протоколу // ЭКО. 2014. № 7 (481). С. 180-189.

Порфирьев Б. Н. «Зеленый» фактор экономического роста в мире и в России // Проблемы прогнозирования. 2018. № 5 (170). С. 3-12.

Порфирьев Б. Н., Рогинко С.А. Энергетика на возобновляемых источниках: перспективы в мире и в России // Вестник Российской академии наук. 2016. Т. 86. № 11. С. 963-971.

Пыюжев А.И. Лесной комплекс России в зеркале Майского указа 2018 г.: а будет ли прорыв? // Journal of Economic Regulation (Вопросы регулирования экономики). 2019. Т. 10. № 1. С. 77-89. DOI: 10.17835/2078-5429.2019.10.1.077089

Романовская А.А., Трунов А.А., Коротков В.Н., Карабань Р.Т. Проблема учета поглощающей способности лесов России в Парижском соглашении // Лесоведение. 2018. № 5. С. 323-334. DOI: 10.1134/S0024114818050066

Федоров Б.Г. Российский углеродный баланс. М.: Научный консультант, 2017. $82 \mathrm{c}$.

Чугункова А.В., Пьжев А.И., Пьжева Ю. И. Влияние глобального изменения климата на экономику лесного и сельского хозяйства: риски и возможности // Актуальные проблемы экономики и права. 2018. Т. 12. № 3. С. 523-537. DOI: $10.21202 / 1993-047 X .12 .2018 .3 .523-537$ 
Швиденко А. 3., Щепащенко Д.Г. Углеродный бюджет лесов России // Сибирский лесной журнал. 2014. № 1. С. 69-92.

Brown K., Adger W.N., Cinner J.E. Moving climate change beyond the tragedy of the commons // Global Environmental Change. 2019. Vol. 54. Pp. 61-63. DOI: 10.1016/j.gloenvcha.2018.11.009

Cook J. et al. Consensus on consensus: a synthesis of consensus estimates on human-caused global warming // Environmental Research Letters. 2016. Vol. 11. No. 4. P. 048002. DOI: 10.1088/1748-9326/11/4/048002

Hilbe C., Šimsa Š., Chatterjee K., Nowak M.A. Evolution of cooperation in stochastic games // Nature. 2018. Vol. 559. No. 7713. Pp. 246-249. DOI: 10.1038/ s41586-018-0277-x

Hardin G. The tragedy of the commons // Science. 1968. Vol. 162. Pp. 1243-1248.

Grunewald N., Martinez-Zarzoso I. Did the Kyoto Protocol fail? An evaluation of the effect of the Kyoto Protocol on $\mathrm{CO}_{2}$ emissions // Environment and Development Economics. 2016. Vol. 21. No. 1. Pp. 1-22. DOI: 10.1017/S1355770X15000091

Lenton T. M. et al. Tipping elements in the Earth's climate system // Proceedings of the National Academy of Sciences. 2008. Vol. 105. No. 6. Pp. 1786-1793. DOI: 10.1073/pnas.0705414105

Lewis S.L., Wheeler C.E., Mitchard E.T.A., Koch A. Restoring natural forests is the best way to remove atmospheric carbon // Nature. 2019. Vol. 568. No. 7750. Pp. 25-28. DOI: 10.1038/d41586-019-01026-8

Pan Y. et al. A Large and Persistent Carbon Sink in the World's Forests // Science. 2011. Vol. 333. No. 6045. Pp. 988-993. DOI: 10.1126/science.1201609

Porfiriev B. Climate change as a major slow-onset hazard to development: An integrated approach to bridge the policy gap // Environmental Hazards. 2015. Vol. 14. No. 2. Pp. 187-191. DOI: 10.1080/17477891.2015.1019823

Shvidenko A., Schepaschenko D., Kraxner F., Fritz S. Full verified carbon account of forest ecosystems: An attempt to assess uncertainty. In: 4th International Workshop on Uncertainty in Atmospheric Emissions. Conference Proceedings. 7-9 October 2015. Krakow, Poland. Pp.1-8.

Статья поступила 03.07.2019.

Для цитирования: Пьжев А.И., Ваганов Е.А. Роль российских лесов в реализации Парижского климатического соглашения: возможности или риски?// ЭКО. 2019. № 11. С. 27-44. DOI: 10.30680/ECO0131-7652-2019-11-27-44.

\section{Summary}

Pyzhev, A. I., Cand. Sci. (Econ.), Vaganov, E.A., Doct. Sci. (Biology), Siberian Federal University, Krasnoyarsk

\section{Global Climate Change Economics: The Role of Russian Forests}

Abstract: The Paris Agreement (2015) under the UN Framework Convention on Climate Change has set a new format for international coordination of efforts to manage greenhouse gas emissions subject to diverse national interests and the imperative of widespread transition to low-carbon energy. The paper considers a possibility of using the potential for carbon sequestration by Russian forests from 
the point of view of implementing Russia's obligations under the 2015 Paris Climate Agreement. It is shown that achieving this goal subject to the interests of the national economy development requires development of methods and information base for estimating the carbon budget of Russian forests. It is proposed to launch formation of a comprehensive strategy for the country's participation in implementation of the Paris Agreement, considering both the goals of technological modernization of the energy sector and increasing the forest area, as well as complete and accurate information about their quality.

Keywords: climate change economics; Paris Agreement 2015; forestry economics; carbon sequestration; greenhouse gases

\section{References}

Brown, K., Adger, W.N., Cinner, J.E. (2019). Moving climate change beyond the tragedy of the commons. Global Environmental Change. Vol. 54. Pp. 61-63. DOI: 10.1016/j.gloenvcha.2018.11.009

Chugunkova, A.V., Pyzhev, A.I., Pyzheva, Yu.I. (2018). Impact of global climate change on forestry and agriculture economics: risks and opportunities. Actual Problems of Economics and Law. Vol. 12. No. 3. Pp. 523-537. DOI: 10.21202/1993047X.12.2018.3.523-537. (In Russ.).

Cook, J. et al. (2016). Consensus on consensus: a synthesis of consensus estimates on human-caused global warming. Environmental Research Letters. Vol. 11. No. 4. P. 048002. DOI: 10.1088/1748-9326/11/4/048002

Fedorov, B.G. (2017). Russian carbon balance. Moscow, Scientific Advisor Publ. 82 p. (In Russ.).

Grunewald, N., Martinez-Zarzoso, I. (2016). Did the Kyoto Protocol fail? An evaluation of the effect of the Kyoto Protocol on $\mathrm{CO}_{2}$ emissions. Environment and Development Economics. Vol. 21. No. 1. Pp. 1-22. DOI: 10.1017/ S1355770X15000091

Hardin, G. (1968). The tragedy of the commons. Science. Vol. 162. Pp. 1243-1248.

Hilbe, C., Šimsa, Š., Chatterjee, K., Nowak, M.A. (2018). Evolution of cooperation in stochastic games. Nature. Vol. 559. No. 7713. Pp. 246-249. DOI: 10.1038/s41586-018-0277-x

Kokorin, A., Lugovaya, D. (2018). $\mathrm{CO}_{2}$ uptake by Russian forests in the context of the Paris Agreement. Sustainable Forestry. No. 2 (54). Pp. 13-18. (In Russ.).

Lenton, T.M. et al. (2008). Tipping elements in the Earth's climate system. Proceedings of the National Academy of Sciences. Vol. 105. No. 6. Pp. 1786-1793. DOI: 10.1073 pnas.0705414105

Lewis, S.L., Wheeler, C.E., Mitchard, E.T.A., Koch, A. (2019). Restoring natural forests is the best way to remove atmospheric carbon. Nature. Vol. 568. No. 7750. Pp. 25-28. DOI: 10.1038/d41586-019-01026-8

Makarov, I. (2011). Double dividend instead of global altruism. Russia in Global Affairs. Vol. 9. No. 4. Pp. 142-154. (In Russ.).

Malysheva, N.V., Moiseev, B.N., Filipchuk, A.N., Zolina, T.A. (2017). Methods for estimating the carbon balance in forest ecosystems and the possibility of using them to calculate the annual carbon sequestration. Forestry Bulletin. Vol. 21. No. 1. Pp. 4-13. DOI: 10.18698/2542-1468-2017-1-4-13. (In Russ.). 
Motosova, E.A., Potravnyi, I.M. (2014). Pros and cons of introducing a carbon tax: foreign experience and Russia's position on the Kyoto Protocol. ECO. No. 7 (481). Pp. 180-189. (In Russ.).

Pan, Y. et al. (2011). A Large and Persistent Carbon Sink in the World's Forests Science. Vol. 333. No. 6045. Pp. 988-993. DOI: 10.1126/science.1201609

Porfiriev, B. (2015). Climate change as a major slow-onset hazard to development: An integrated approach to bridge the policy gap. Environmental Hazards. Vol. 14. No. 2. Pp. 187-191. DOI: 10.1080/17477891.2015.1019823

Porfiriev, B.N. (2018). "Green" factor of economic growth in the world and in Russia. Problemy Prognozirovaniya. No. 5 (170). Pp. 3-12. (In Russ.).

Porfiriev, B.N., Roginko, S.A. (2016). Energy on renewable sources: prospects in the world and in Russia. Herald of the Russian Academy of Sciences. Vol. 86. No. 11. Pp. 963-971. (In Russ.).

Pyzhev, A.I. (2019). Forest complex of Russia in the mirror of the May decree of 2018: is it worth waiting a breakthrough? Journal of Economic Regulation. Vol. 10. No. 1. Pp. 77-89. DOI: 10.17835/2078-5429.2019.10.1.077-089. (In Russ.).

Romanovskaya, A.A., Trunov, A.A., Korotkov, V.N., Karaban', R.T. (2018). The problem of accounting for the absorptive capacity of Russian forests in the Paris Agreement. Russian Journal of Forest Science (Lesovedenie). No. 5. Pp. 323-334. DOI: 10.1134/S0024114818050066. (In Russ.).

Shvidenko, A.Z., Shchepashchenko, D.G. (2014). The carbon budget of the forests of Russia. Siberian Journal of Forest Science. No. 1. Pp. 69-92. (In Russ.).

Shvidenko, A., Schepaschenko, D., Kraxner, F., Fritz, S. (2015). Full verified carbon account of forest ecosystems: An attempt to assess uncertainty. In: 4th International Workshop on Uncertainty in Atmospheric Emissions. Conference Proceedings. 7-9 October 2015. Krakow, Poland. Pp.1-8.

Virt, D.A. (2017). Paris Agreement as a New Component of the UN Climate Regime. International Organisations Research Journal. Vol. 12. No. 4. Pp. 185-214. (In Russ.).

Zamolodchikov, D. (2011). Systems for estimating and predicting carbon stocks in forest ecosystems. Sustainable Forestry. No. 4 (29). Pp. 15-22. (In Russ.).

Zamolodchikov, D.G., Grabovskiy, V.I., Kraev, G.N. (2011). Dynamics of the carbon budget of Russian forests over the last two decades. Russian Journal of Forest Science (Lesovedenie). No. 6. Pp. 16-28. (In Russ.).

For citation: Pyzhev, A.I., Vaganov, E.A. (2019). Global Climate Change Economics: The Role of Russian Forests. ECO. No. 11. Pp. 27-44. (In Russ.). DOI: 10.30680/ECO0131-7652-2019-11-27-44. 